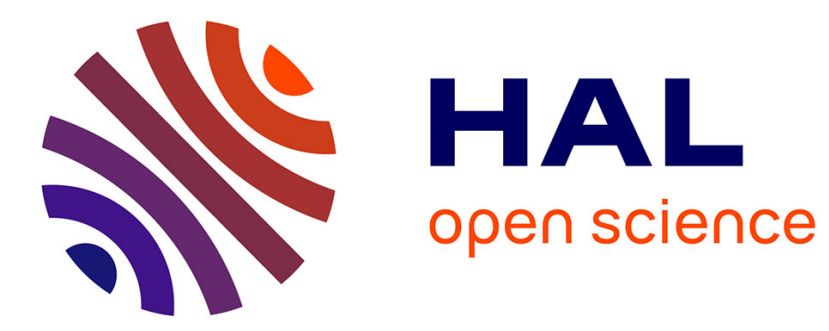

\title{
Conceptual Design of the Technical System Using Complementary Use of TRIZ Function Analysis and Patent Information
}

Sehoon Cho, Kyeongwon Lee, Yongwon Song

\section{To cite this version:}

Sehoon Cho, Kyeongwon Lee, Yongwon Song. Conceptual Design of the Technical System Using Complementary Use of TRIZ Function Analysis and Patent Information. 19th International TRIZ Future Conference (TFC), Oct 2019, Marrakesh, Morocco. pp.240-256, 10.1007/978-3-030-324971_20. hal-02905564

\author{
HAL Id: hal-02905564 \\ https://hal.inria.fr/hal-02905564
}

Submitted on 23 Jul 2020

HAL is a multi-disciplinary open access archive for the deposit and dissemination of scientific research documents, whether they are published or not. The documents may come from teaching and research institutions in France or abroad, or from public or private research centers.
L'archive ouverte pluridisciplinaire HAL, est destinée au dépôt et à la diffusion de documents scientifiques de niveau recherche, publiés ou non, émanant des établissements d'enseignement et de recherche français ou étrangers, des laboratoires publics ou privés.

\section{(c)(1)}

Distributed under a Creative Commons Attribution| 4.0 International License 


\title{
Conceptual design of the technical system using complementary use of TRIZ function analysis and patent information
}

\author{
Sehoon $\mathrm{CHO}^{1[82-10-2712-7560]}$, Kyeongwon $\mathrm{LEE}^{2}$ and Yongwon $\mathrm{SONG}^{3}$ \\ ${ }^{1}$ Hanwha Precision Machinery, Seongnam-Si, Gyeong-Do, South Korea \\ Ph.D. student at Korea Polytechnic University \\ sehoon.cho@hanwha.com,sh68.cho@gmail.com \\ ${ }^{2,3}$ Korea Polytechnic University, \\ Siheung City, Gyeonggi-Do, South Korea
}

\begin{abstract}
In general, patents are the outcome of research and development. TRIZ is making a real contribution to solving many problems in new research and development. Such contributions create new patents. Patent and TRIZ have an interdependent relationship from the beginning. In most cases, TRIZ will have a chance to contribute when there is a real engineering problem or when the problem is expected. This study attempts to verify that the above-mentioned relationships are made more active by increasing the interaction, and that the technology systems we want and planned are optimized more quickly. Especially, it is useful in the initial concept design phase of the product, and it is more useful in the new product design situation where the background knowledge of the product or the design experience is low or not. In brief, we propose a tear-down analysis of products that are most similar to the target technology system, or search for prior patents based on 'technology tree' and function. The patent research will acquire the keywords necessary for the patent search by analyzing the function or performance keyword and the similar product by the new VOC, VOB. Through this process, the core technology necessary for the initial conceptual design of the target system and the patent information to be utilized are obtained. From the obtained patent information, we get a hint about the technical components and the interaction relationship for the new system. This facilitates conceptual design for the new technology system.
\end{abstract}

Keywords: Conceptual Design; Tear down analysis; Patent Search and Analysis; Optimal Design; Function Analysis; Trimming; Design Around; FOS

\section{$1 \quad$ Introduction}

\subsection{Patent and TRIZ}

In general, patents are the outcome of research and development, and TRIZ is known as a problem solving methodology obtained through studying the characteristics and patterns of a large number of patents. TRIZ is making a real contribution to solving 
many problems in new research and development. Such contributions create new patents. Patent and TRIZ have an interdependent relationship from the beginning. In most cases, TRIZ will have a chance to contribute when there is a real engineering problem or when the problem is expected. This relationship is often regarded as a passive relationship. This study attempts to verify that the above-mentioned relationships are made more active by increasing the interaction, and that the technology systems we want and planned are optimized more quickly.

\subsection{Patent information}

Patents and their legislation have different standards and operating systems in different countries. This paper briefly examines the meaning of patent information in the US patent system as an example and introduces the basis of what this paper uses. Normally, when a patent application is filed with the US Patent and Trademark Office (PTO), it is firstly confirmed whether the PTO's employee conforms to the format required for the application, and an examiner will be appointed to examine the relevant technical field. The examiner will first look at the specification and the claim, and find that the invention is ' 35 U.S.C. $\$ 101$ 'of the patent. The examiner shall review the details of the description and review the prior art after reviewing the conformity to the requirements for registration (35 U.S.C. \$112). The examiner will review the research result to see if there is a "novelty" (35 USC $\S 102$ ) and "unobviousness" (35 USC $\S 103$ ) and then decide whether to issue a patent or reject it.

"The specification shall contain a written description of the invention, and of the manner and process of making and using it, in such full, clear, concise, and exact terms as to enable any person skilled in the art to which it pertains, or with which it is most nearly connected, to make and use the same, and shall set forth the best mode contemplated by the inventor of carrying out his invention." This is summarized in (a) a "written description" requirement, (b) a "enablement" requirement, and (c) a "best mode" requirement. Here, the enablement requirement can be divided into the "how to make" requirements and the "how to use" requirements, which will enable a person skilled in the art to make and use an invention It should be taught in the specification. The case is explained as follows.

"To be enabling, the specification of a patent must teach those skilled in the art how to make and use the full scope of the claimed invention without 'undue experimentation." In re Wright, 999 F.2d 1557, 1561 (Fed. Cir. 1993).

In the end, it can be seen that the patent information contains essential components for its specific function, performance implementation and technical effect, its interactions and concrete examples. Analyzing one patent means analyzing one technology system. The elements constituting the claim are components of the technical system, and the contents described in order to obtain the function and performance describe the interaction of the components. 


\subsection{Use of patent information and problem solving}

Patent information having the legal requirements described above has been utilized in various ways by industry.

\subsubsection{Prior Patent Research (PSR)}

Before proceeding with research and development, basically, developers list up the products to be used for business planning or R \& D and the technologies used in the products and perform 'Prior Art Research'. Researchers look for the presence of prior art or patents that are the same or similar to the technology of interest. If there are patents that are substantially the same as or similar to the technology of interest in the results, a review of the patent matter should be done first.

The person in charge of the assignment judges whether or not to do 'Design around' to solve the patent problem. Another example of use is that prior to filing the invention with the Patent Office, the inventor or the patent expert of the company conducts 'Prior Art / Patent Research' and judges whether the application is filed at the Patent Office according to the result of the review.

\subsubsection{Patent Map (PM)}

Company researchers or planning departments use patent information to prepare new projects or to investigate industry trends. It draws a kind of map with time and technology center with patent information. The company searches and analyzes the patent information on the subject such as country, competitor, product, technology, specific researcher, period, region according to purpose. The results of this research provide information that suggests the flow of development of a specific technology, a technology strategy of a company, a patent strategy, a portfolio of a business, or a future product. It also allows you to predict which researchers are organized and when new features will be added to which products.

\subsubsection{Function oriented Search (FOS)}

FOS is one of the useful problem solving methods to find out from various information (resources) when there is a task to be solved or a function required in one technical system is determined.

FOS is similar to 'Prior Patent Search', but it defines the function to be searched and performs function-oriented research. Function-Oriented Search (FOS) is a problem solving tool based upon identifying existing technologies worldwide, using function criteria [1]. If the problem (task) to be solved is defined, investigate whether there is an identical or similar case attempted for the problem solving (function). The flow consists of four steps and there are detailed steps. As an example, proceed as follows. Each step can have sub-steps.

Table 1 shows that the FOS is modified to correspond to the patent database. The following table shows a brief table of methods and procedures that I use mostly. 
Table 1. Function-Oriented Search (FOS)

\begin{tabular}{|c|c|c|}
\hline Main Steps & Sub Steps & Guidance \\
\hline \multirow{2}{*}{$\begin{array}{l}\text { Definition of } \\
\text { main function }\end{array}$} & Definition of key issues to be solved & \\
\hline & Define the function to be performed & $\begin{array}{l}\text { Combination of words to be } \\
\text { searched and search expression }\end{array}$ \\
\hline \multirow{2}{*}{$\begin{array}{l}\text { Generalization } \\
\text { of function }\end{array}$} & $\begin{array}{l}\text { Change function to be performed to general- } \\
\text { ized function }\end{array}$ & $\begin{array}{l}\text { what }(\text { subject })+\text { predicate, } \\
\text { maintenance or change of pa- } \\
\text { rameter }\end{array}$ \\
\hline & $\begin{array}{l}\text { Key word extraction from the point of sub- } \\
\text { stance-function-problem }\end{array}$ & \\
\hline \multirow[b]{2}{*}{$\begin{array}{c}\text { Find case and } \\
\text { idea }\end{array}$} & International patent (technology) survey & Using patent classification table \\
\hline & Selection of Leading Area & $\begin{array}{l}\text { Selection of industry group that } \\
\text { is widely used by quantitative } \\
\text { analysis }\end{array}$ \\
\hline \multirow[b]{2}{*}{ Create solution } & $\begin{array}{l}\text { Select the most suitable technology / solution } \\
\text { to perform necessary functions }\end{array}$ & \\
\hline & $\begin{array}{l}\text { Identification of possible problems in apply- } \\
\text { ing selected technology and application of } \\
\text { solution }\end{array}$ & \\
\hline
\end{tabular}

The Function-Oriented Search is to find the problem and the functions, hits, or principles needed to solve it. However, if there is only a principle or function itself to solve the contradiction, new sub-problems may arise in the process of using them. So far, the purpose and effects of some cases of using patent information can be basically summarized as a process in which a rough technical system is defined, finding a comparative object, or finding similarities of some of the functions.

There are various examples and studies that TRIZ is very useful as a tool and method for dealing with patent problems $[4,5,6,7]$. It has also been verified through various attempts and exploits that patent information is useful for solving problems [15]. In this paper, we are going to use patent information to solve the problems of the existing technology system, that is, the initial conceptual design to achieve it when a new function or performance is required.

\subsection{New Threat of Patent Information}

The obtained patent information is beneficial but at the same time has new risk factors. Because patents are information that is proprietary to the technology for a certain period of time, users should be very careful according to their usage patterns.

There are a number of studies that use TRIZ to solve problems in patent disputes $[18,19,20]$. There are cases where research results are used in practice. However, the fact that the problem is resolved in the solution of the patent law and commercial problem solving are often different. It is desirable to judge whether all problems or tasks are solved based on the actual profit or value obtained from the whole point of view. It should not be judged simply by technically solving the problem. Simply implementing the desired functionality and performance does not solve the problem. The solution 
should not create serious subsequent problems. In particular, if the contradictory solution or concrete solution created or presented by the TRIZ expert infringes the patent of the third party, it becomes a new big problem. If a new problem can not be resolved in a timely manner, or if the resources and costs needed to solve it exceed the problem owner's expectations, then the attempted solution is not a solution. Therefore, when dealing with patent information, it should be cautious of the claim.

Patent information is the best information resource that must be utilized in the process of solving technical problems. The reason was verified by case and theoretically. In particular, there is the usefulness of patent information at the point of conceptual design without concrete problem situations. It is one of the implications of this paper that the existing application area extends to a wider area. The solution derived through this process will have both applicability and patentability at the same time.

\section{The reality of the planning of a typical new product or system}

Research and development of most technical systems starts with people's needs. Whether it is convenience, comfort, or pleasure, it comes from seeking something better developed from the current state. A technology system that people are currently using or have experienced in the past is the starting point. It may not be a problem of the present technology system itself. It is a new requirement and expectation for technical systems by a human.

\subsection{Design motivation for new systems}

Voice of Customer (VOC) and Voice of Business (VOB) have similar and different appearance, but individual keywords are the same. That is, the new functions, improved performance, convenience, low price, and new value are the keywords. In this case, low price has a difference in terms of suppliers and recipients in 'manufacturing cost' and 'purchase price', but the essence is the same. Specific efforts or attempts to reach new demands or expectations are made in the laboratory. The problem is that there are various constraints and new problems in the process of such efforts or attempts. Development period, quality verification, product price, manufacturing cost, technology barrier, patent problem, and the like.

Especially when the new expectations are beyond the developers' experience, skills and knowledge. Sometimes the content and desired level of a technical problem goes beyond common sense. These situations can be called contradictory situations.

\subsection{New Needs and New Challenges}

Most of the work in the laboratory of the company is the extension of the existing company's products. Much of the additional functionality and performance enhancements are made. However, when existing products do not meet the ongoing needs and expectations of customers in the marketplace, or when the appearance of alternative systems is anticipated, new challenges arise. Also, when a competitor has already made a new 
product and put it on the market, it will reach similar difficulties. Sometimes it can be a challenge to develop without causing conflicts with competitors' patents.

Difficulty here can mean that developers need to work with new approaches and other unfamiliar ways. It may be a situation that requires different approaches and new methods and efforts compared to the technology, experience and knowledge contained in the current product. In many cases, the company may be in a situation where it needs to establish new business strategies or plan new products. It is foolish to expect new products using the same methods and materials [Albert Einstein].

\subsection{Beginning and Limitations of Conceptual Design}

In order to develop most new products, concept design will be done first. It is practically very difficult to manufacture a product with a complex technology system in a single attempt. In particular, the needs and expectations of customers are often unclear in the marketplace, and sometimes requests or expectations from managers are frustrating for developers. Researchers strive to establish clearer technical goals from VOCs in the market and from VOBs of managers. The beginning of conceptual design is designed by a few people who are rich in experience, knowledge and skills relative to the business or product or technology involved in the organization. They define the approximate composition, function, and performance of a product that reflects more or less specific requirements from VOCs and VOBs. Most companies prepare their business and products with a long-term plan. Predict market and technology trends and develop key technologies in advance, bringing new products to market in a timely manner. There are prepared developers and engineers in this process.

At times, however, there is no planner suitable for the company. Even if there are designers who have similar experience and knowledge, it is difficult to predict the actual technical problems that will be encountered in developing the conceptual designs made by them and developing them to make actual products. Many issues remain, such as the required period of time for the final product to be made, money, developer, major component supply, and so on. In actual product development, it is very difficult to obtain results that satisfy both VOC and VOB. Developers study functionality and performance as final goals, and product planners plan products for sales and profit. Products with potential problems are under development. Most of the time when the market demands and the timing and methods of supplying are inconsistent. Therefore, despite the fact that many products are planned in technology management, the proportion of products that are successful in the market is very low, so that there are cases in which it is not certain whether a product that succeeds in actual market is thoroughly planned. Figure 1 is an example of statistics showing this situation. 


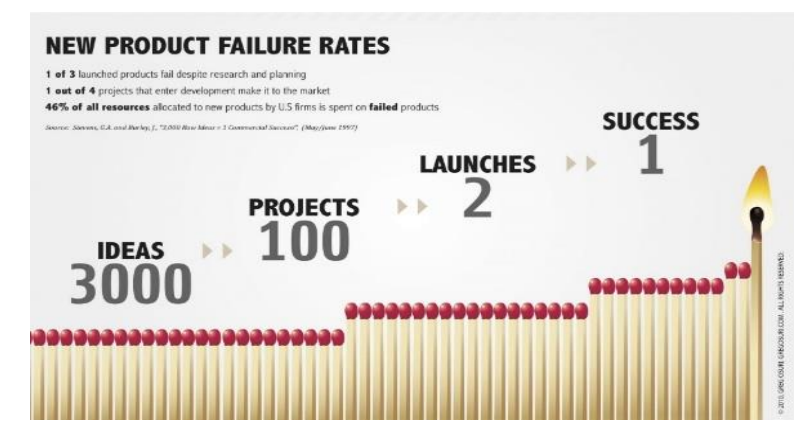

Fig. 1. New product failure rate [2]

These results, together with the need for the development of a new methodology, continue to analyze the successful cases of the relatively good group and make them more aware of the need for active use. Many researchers have attempted to combine the potential difficulties of conceptual design with a variety of methodologies to solve problems and errors in the process. Samsung incorporated several research methodologies, including 'Technology Road Map' and 'Technology Tree' around 2000.

In addition, research has been conducted on how various methodologies can be applied in the process of delivering products and services from mid- and long-term business planning to customers. Figure 2 shows the appropriate time for the various methodologies to be used step by step throughout the entire R \& D process [22]. Here, 'Technology Tree' has a feature that combines 'Logic Tree' and 'Technical classification'. It means that the technology and the components of a technology system are structured logically and systematically.

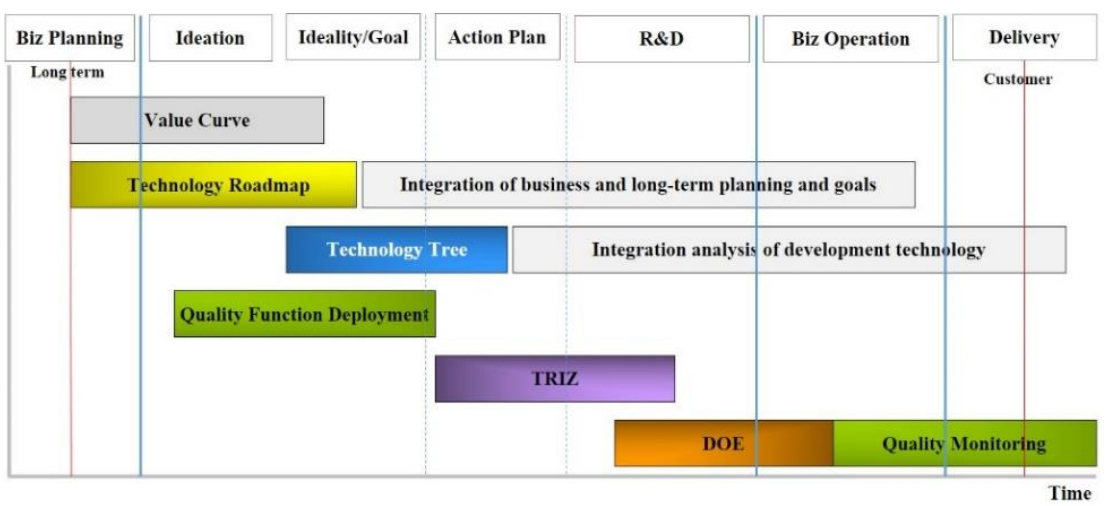

Fig. 2. R \& D process and methodology of research methodology [22]

'Technology Tree' can be a good tool to systematically view the current technology system, to improve the technical system by grasping the level of research field, element technology, adding or removing new functions, and reducing manufacturing cost. Figure 3 is a conceptual diagram that predicts which element technology needs further research and which product is likely to be applied [22]. Interaction or combination of these methodologies can be a good approach for predicting future products or selecting 
targets for strategic technology development. In addition, by combining 'Quality Function Deployment' and 'Technology Tree', VOC can be easily converted into an engineering language and contribute to understanding the related element technology. However, it does not provide the necessary methods, hints or layouts for designing new products for new VOCs or VOBs.

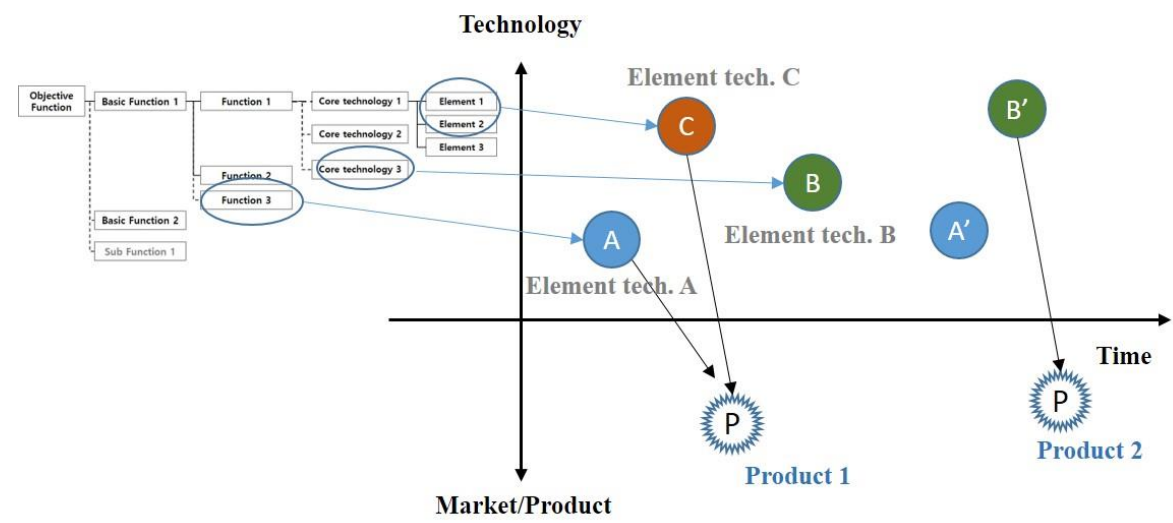

Fig. 3. Technology Tree application in Technology Roadmap [22]

In the field of TRIZ, various methods and applications of tools and new attempts are continuing. It is not a real solution if existing methods create new problems or have potential problems. In Part 7 (7.2) of ARIZ [3], Altshuller asks whether each solution meets the requirements of IFR-1. Recently, Pahl and Beitz proposed the hybrid method of TRIZ method and SDA (Systematic Design Approach) [12]. Fundamental understanding of conceptual design, safety and problem solving resulted to a systematic yet simple optimization process simultaneously changing the perspective of creative problem solving as a whole [12].

Segmenting the system and structure of a prototype into F3(Form-Fit-Function) can help designers plan and organize resources, such as technology concept, incorporation of new materials and time taken to develop the system pertaining to the constraints [13]. The combined methodology of TRIZ with the constraint-based approach sanguinely increases the capability to design with constraint management [13]. Also, an integrated model of the Conceptual Design Process was presented, which is based on QFD, Functional Analysis and TRIZ [9, 10]. Here, the information obtained during the Functional Analysis was used to identify the product structure which reveals the technical parameters needed for the QFD process [9]. This is very useful in deriving the functions required in a technical system in conjunction with a contradiction matrix.

Another attempt has been proposed by the Analytical Hierarchy Process (ARI) to enhance the three main stages of the TRIZ methodology: problem definition, root cause identification and solution generation [21]. There are also studies to explore the symbiotic relationship between axiomatic design and TRIZ, to utilize the strengths of each method, and to complement vulnerabilities [11]. However, there is a fundamental need for professional experience such as various situations, constraints, and resource analysis to be considered in conceptual design [14]. 
Until now, various methodologies including TRIZ have been integrated or partially complemented. And the results obtained good results corresponding to the purpose of each attempt. Normally, the company checks the business risk through 'Freedom To Operate Analysis(FTO)' before the product is released to the market [15]. Likewise, the final stage of problem solving requires patent analysis. In other words, we must review whether the beneficial solution infringes the patents of third parties.

\section{Additional attempts at conceptual design}

It is very useful to use some TRIZ tools, including essential patent information at the stage of planning a product or technology system in terms of the final Goal and total cost, before specific engineering problem exists. This procedure minimizes new risks or problems in the use of the final solution.

\subsection{Basic Flow for the conceptual design}

An in-depth analysis of the product planning stage in conceptual design has a) Identification of needs and opportunities, b) Resource assessment, c) Definition of a first product requirement list to be updated during the design process [14]. The TRIZ-SDA Conceptual Design Framework (CDF) consists of eight steps [16]: a) Identifying and Understanding, b) Formulating Ideas and Finding Solution, and c) Evaluating and Confirming. Table 2 shows the flow of the method presented in this paper as 4 main steps and 8 sub steps. This can be called patent information-based problem solving (PIPS).

Table 2. Patent Information-based Problem Solving

\begin{tabular}{|c|c|c|}
\hline Main Steps & Sub Steps & Guidance \\
\hline \multirow{3}{*}{$\begin{array}{l}\text { Definition of Functional } \\
\text { Requirements } \\
\text { in System }\end{array}$} & VOC \& VOB Review & QFD, HOQ, ENV \\
\hline & Similar / Basic System Review & $\begin{array}{l}\text { Tear Down Review (TDR) analy- } \\
\text { sis } \\
\text { Gap information }\end{array}$ \\
\hline & $\begin{array}{l}\text { Technology Tree Draft for Target } \\
\text { System }\end{array}$ & $\begin{array}{l}\text { Keywords List up based on Func- } \\
\text { tion }\end{array}$ \\
\hline \multirow{2}{*}{$\begin{array}{c}\text { Generalization / Search } \\
\text { of the Functions }\end{array}$} & Prior Art (Patent) Search & World Patent Database, FOS \\
\hline & $\begin{array}{l}\text { Patent Information Classification } \\
\& \text { Analysis }\end{array}$ & IPC. CPC, Grouping \\
\hline \multirow{2}{*}{ Developing Solution } & Function Analysis & Trimming \\
\hline & Implementation the Solution & Resource Analysis \\
\hline Solution Enhancement & Patent Apply \& Portfolio & Claim Structuring \\
\hline
\end{tabular}




\subsection{Detail Flow for the conceptual design}

The flow of problem solving using patent information presented in this paper and presented experimentally is explained in more detail as follows.

\subsubsection{VOC \& VOB Review}

As at the roof of the HOQ are identified the contradictory relationships among the design parameters, it seems straightforward to use these identified contradictory parameters to find a link to Altshuller's Technical Contradiction Matrix [9]. These can be used to derive functional and performance words from the VOCs and VOBs that the customer ultimately expects or requires. Of course, you can create a list using the ENV (Element, Name of Feature, Value) Model. It is desirable to draw as many functional words as possible.

\subsubsection{Similar/Basic System Review}

It is difficult to design a new technology system from the start with general knowledge and skills. Therefore, it is recommended to find a system that is similar to the function and performance currently required. If the actual product is obtained, test the function and performance before disassembly, and obtain the gap information of required function and performance. Then, the decomposition process is performed while sequentially estimating the components and functions. This Tear Down Review (TDR) analysis can be a very important process in determining functionality, performance, structure, components, materials and pricing information from a similar system to a new target system. Electronic components provide individual manufacturers and pricing information, and PCBs can infer module-level functionality. It is appropriate that TDR should be conducted by three or four people with different technical fields.

\subsubsection{Technology Tree(TT) Draft for Target System}

The purpose of this step is to extract the keywords for the function based search. The structural approach to the construction of the technical system can be developed using 'Technology Tree (TT)'. The 'Technology tree' is a method to define functions for the purpose of the system and to organize the detailed functions for implementing the functions and the components for creating each function. When the objective function of a new technology system to be created by a new requirement or need is roughly defined, subdivide it into main functions and additional functions and list the configurations for making each function. Although TT itself does not provide a clue for new ideas or solutions, it is useful for understanding the components for exploring new technology systems as functions. Figure 4 shows the development of the basic TT. TT can be diagrammed with function and performance list, gap information obtained from TDR analysis, unit module information of similar system, component parts, function and performance information. 


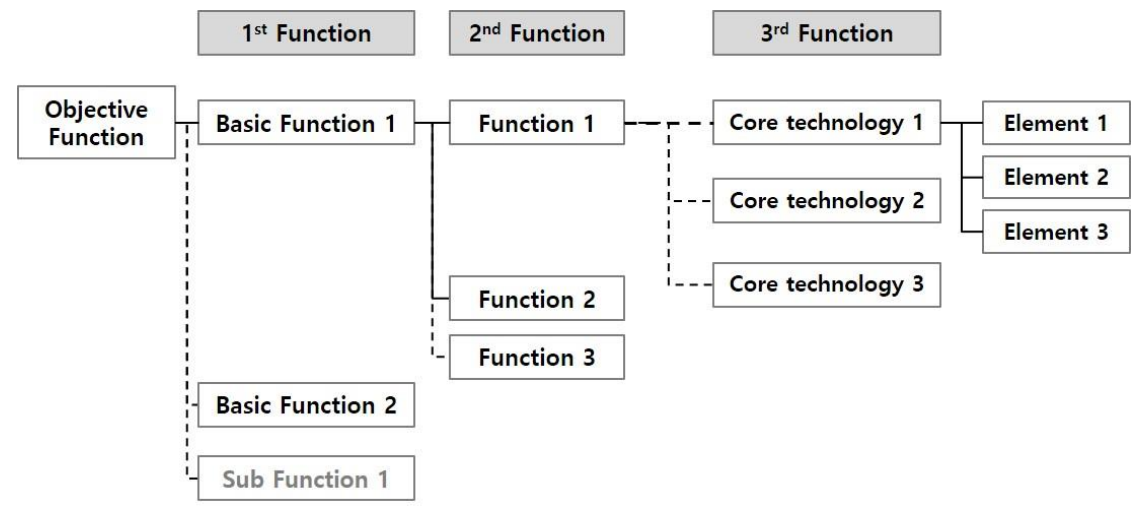

Fig. 4. Technology Tree [22]

\subsubsection{Prior Art (Patent) Search Based on Function}

The TT, which is primarily made, is partially completed with functions and capabilities to meet customer needs and expectations. In other words, there are situations where functions or performances that can be obtained or completed by existing similar systems, as well as features and capabilities that are missing or lack items. Here, functionbased keywords for searching prior art and patents can be extracted. Create a functionbased keyword for each function, and separate the function to be created and the function to be created, respectively. The patent searches are conducted through functionoriented keywords according to the number of kinds of functions to be found. Patent information is provided by the patent office of most countries. Apply FOS well known in TRIZ field.

\subsubsection{Patent Information Classification \& Analysis}

The prior art and the patents found are classified according to the presence or absence of the function. Regardless of the classification, additional procedures should be followed if living patents are consistent with the functionality and performance within the TT Draft. The discovery of the problem patent and the procedure for solving it can be done using the procedures and tools of the previous studies using TRIZ $[18,19,20]$.

The degree of completion of the TT Draft can be increased from the patent information found. First, it is necessary to partially complement the functions and performance learned through the TDR of the similar system to improve the completeness. Functionality and performance inferred from the characteristics or shape of a component may occasionally include errors. It is necessary to analyze the interactions between the components and the components necessary for implementing the existing functions and performance before implementing the new functions and performance. This is essential for resource analysis of the configuration that a subsequent existing system requires and for analyzing interactions between new components for added functionality and performance implementation.

Then analyze patents for missing or incomplete functions in the current TT Draft. Similar configurations will be found in different patents from those described in detail for 
the same or similar functions from multiple patents. From this patent information, we raise the level of completion of TT.

\subsubsection{Function Analysis}

Based on the completed TT, it is possible to analyze the interaction relation with the components, that is, the function analysis of TRIZ. It is possible to derive the technical contradiction and the physical contradiction through the interaction relation between the added component based on the existing component and the existing function and the newly added function. Trimming through system analysis, system optimization can be performed subsequently.

\subsubsection{Implementation the Solution}

The patent information used in the process of this step includes a detailed description of each functional implementation. Thus, such information is the source of information that implements the functionality and performance of the intended technology system without further experimentation or special difficulties. In addition, the functional analysis is deepened, and the system is optimized by performing resource analysis on the components. Subsequent steps will improve the system's completeness through partial detail design if necessary

\subsubsection{Patent Apply \& Portfolio}

In addition, the function of patent application and its components are easily extracted in the process of classifying and analyzing patent information. New patents are created, including interrelated configurations. New variations of patents can be made in various combinations of candidate components in functional implementation.

\section{$4 \quad$ Case Study}

The case of this paper is a case based on VOC or VOB at the business planning stage of the company or university and individual business. Most of the cases are undergoing the development stage for actual commercialization after the planning stage and also the patents have been made. In addition to the following examples, drone, cosmetics, and mechanical systems were also useful for solving real problems and developing patents.

\subsection{Case (1) Video image problem of surveillance camera for outdoor}

The needs of external customers, VOCs, are addressing the problem of losing specific surveillance areas caused by reflected spotlight problems. Most surveillance camera manufacturers have responded to these customer requests to understand them as physical phenomena. It is also installed in a lower area than the installation position in the surveillance camera installation and surveillance area. Despite various attempts to solve the problem, the solution was not obtained. There was a solution that showed some 
effect, but it was not applicable because it caused a lot of manufacturing cost and it affected profit and loss. The problem was that both VOC and VOB were not resolved.
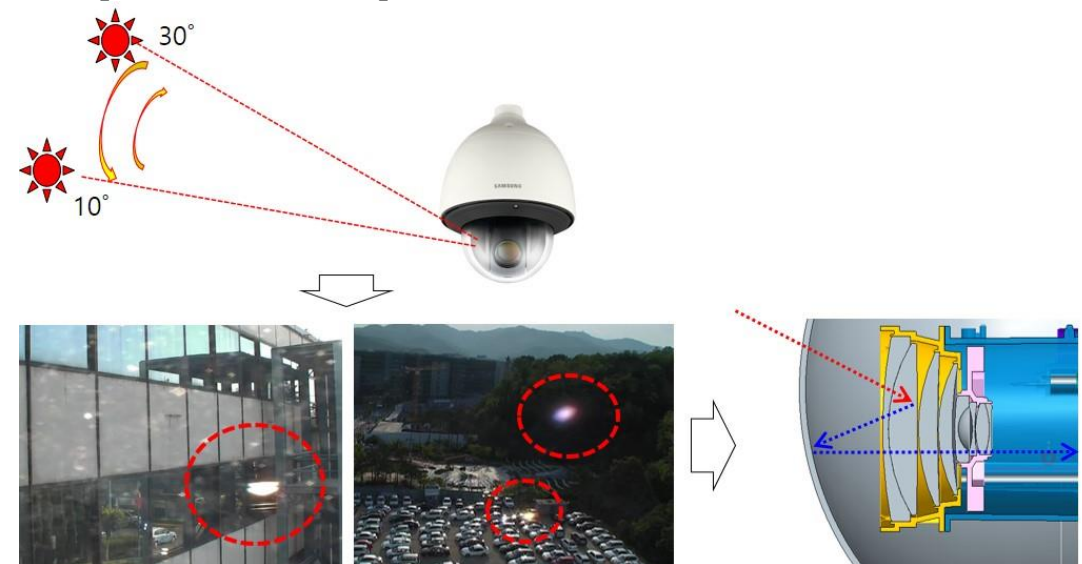

Fig. 5. Reflected spot light problem situation

Figure 5 shows the 'Reflected spot light' problem situation. External installation The surveillance camera sometimes monitors higher than the camera installation position to monitor a large area. The figure illustrates the problem that occurs.

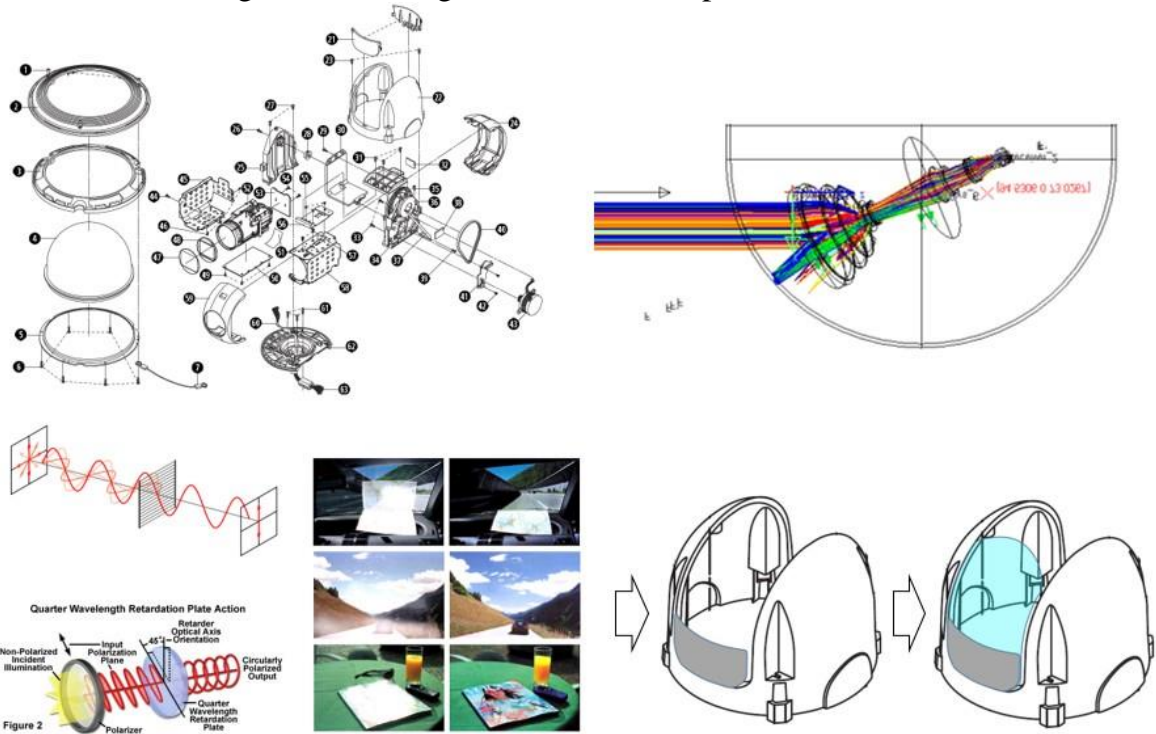

Fig. 6. TDR and problem analysis, solution principles and results

In accordance with the procedure presented in this paper, we performed camera disassembly and function development of our company and competitors, and followed FOS according to the keywords. The patent search did not provide information on the required function implementation. I found information on physical phenomena at Goldfire. However, there is no implementation example, so we tried to analyze the resource 
for implementing new function. Figure 6 illustrates an example of application to real products based on similar phenomena. And Figure 7 shows the actual images comparing the post-war situation according to the application of the solution.
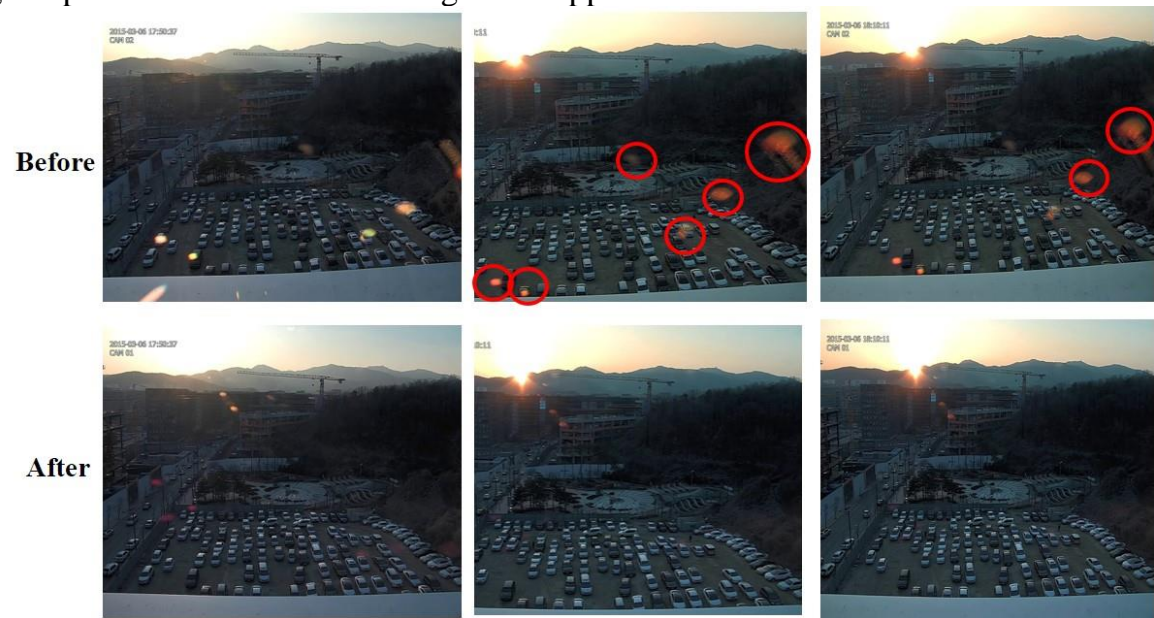

Fig. 7. Comparison of effectiveness of solution application

Case 1's solution has been patented and registered in several countries including the United States [23]. Although a new alternative has been introduced to the market as a replacement for the structure with a transparent cover removed, the technical problem that has not been solved for a long time has been resolved. This has shown that the difficult problem that the company has long given up solving can be solved through TRIZ.

\subsection{Case (2) Large-area graphene transfer system problem}

In 2010, Andre Gamem and Konstantin Novoselov won the Nobel Prize for physics for separating graphene from graphite and became known worldwide. At that time, we were jointly developing large area graphene synthesis technology for commercialization. As shown in Fig. 8, the graphene is synthesized and subjected to a transfer process for actual use. The third party had patents on these processes. There were situations with high royalties and some physical problems. This task was a problem of patent problem solving and improvement of manufacturing method based on VOB.
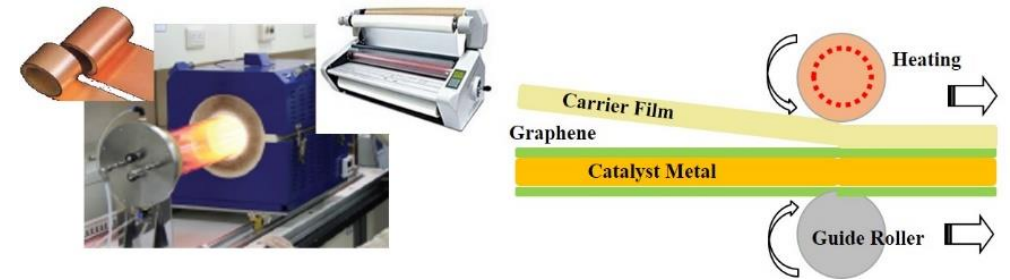

Fig. 8. Concept of transfer method after synthesis of graphene

The serious problem is that the current process is a graphene with a thickness of 0.2 $\mathrm{nm}, 1)$ Degradation of surface properties of graphene after transfer, 2) Surface damage of graphene due to mechanical pressure of roller, 3) the graphene to control the gap and 
the contrast roller. Since the patent has been started, TT was created through TDR and claim chart of experimental manufacturing equipment. The patent search provided a technique for manufacturing thin plates using rollers, but it was not suitable for handling the thickness of graphene. Finally, in the conceptual diagram obtained from TDR as shown in Fig. 9, a method of attaching different thin plates in a physical and noncontact manner was devised from a device for cleaning the surface of the thin plate with the air included in the thin plate manufacturing process.

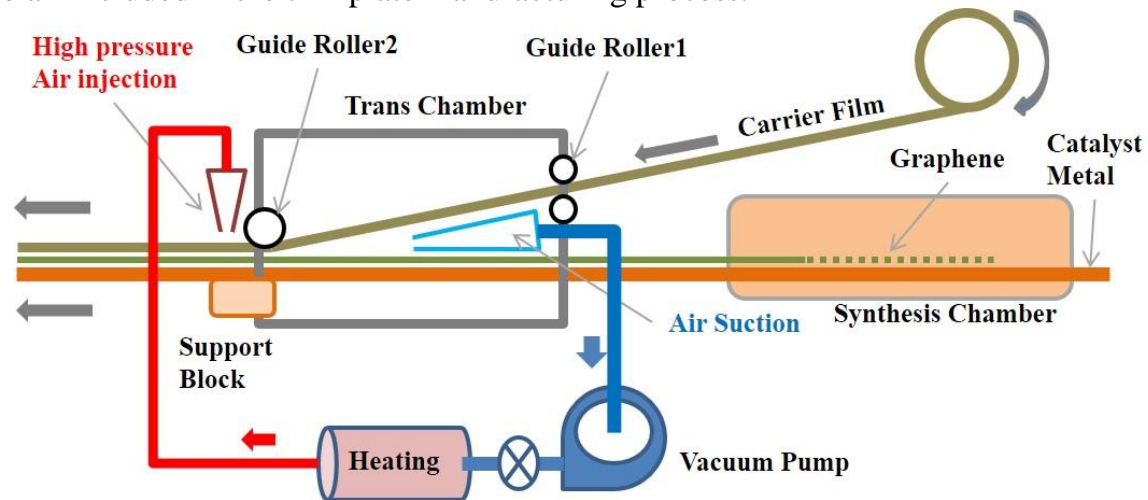

Fig. 9. Conceptual diagram of sheet metal attachment using air pressure

Case 2's solution was filed and registered as a patent in several countries, including the United States [24]. Based on this conceptual design, several processes have been further improved and additional patents have been filed. The solution to this task is to be set up as a subsequent process necessary to produce large area graphene.

In addition to the above examples, many cases have been based on the present study and a good solution has been obtained.

\section{Conclusions}

It is a bit hesitant to define a good problem solver or an appropriate methodology to solve a problem well in a skill area that is familiar to them. It is a true TRIZ expert's role if you find clues in solving unfamiliar technical areas and finding and providing directions and technical principles and resources to solve problems.

VOC, VOB, new business planning, concept design of new products, product configuration in the basic design phase, problems of technical design and technical implementation, there have been various studies and efforts to solve this problem. Rather than new research, it is necessary to use them well and settle and spread with more general methodology. This paper shows how the features of patent information are used in such a process to obtain useful results in the industry and the possibility.

The result of the patent information survey can be expanded to add new resources or analyze in-depth system resources (derivative resources, modified resources), modification of purpose, etc., depending on the presence or absence of necessary information. 
When the required end customer's demand and expected function or performance is set, the technical patents are searched in the patent as the preparation for the technical system design to implement it. In the analysis process, the technology system to be implemented by functional analysis of TDR, Technology Tree and TRIZ We have shown that it is advantageous to classify the necessary functions and to use patent information for empirical information to implement each function.

An additional research task is the attempt to conceptualize a future technology system using patent information, such as new material and its characteristics, new unit module, etc., which have the potential role of resources to create a new technology system of the future.

\section{References}

1. Simon S. Litvin; New TRIZ-Based Tool — Function-Oriented Search (FOS). On 13, Aug 2005

2. New product failure rate ; https://visual.ly/community/infographic/business/new-product-failure-rates

3. Altshuller, G., The Innovation Algorithm: TRIZ, Systematic Innovation and Technical Creativity, Worchester, MA, 1999

4. Ikovenko, S.: Strategies for Patent Busting Using Function Analysis and TRIZ, TRIZCON2004.

5. Ikovenko, S., Kogan, S.: TRIZ Application for Patent Strategies Development. In: Proceedings of TFC p. 427-434, Graz, Austria, Nov. 16-18, 2005

6. Ikovenko, S.; Kogan, S: Patent Practices of Addressing Doctrine of Equivalents and Its Substitutes with G3:ID/TRIZ, TRIZfuture2006.

7. Ikovenko, S. TRIZ Application for IP Strategies Development, Referat to obtain the TRIZ master title. Boston 2006

8. Young Teak Park and Kum Hoan Kuk; Structure Development of Systematic Conceptual Design Process for Designing Engineering Systems. In: Journal of the Korean Society of Precision Engineering v.24 no.9 = no.198 ,pp. 86 - 94, 2007

9. Leon-Rovira, N. ; Aguayo, H. ; A new Model of the Conceptual Design Process using QFD/FA/TRIZ. In: Quality function deployment 1998 ,pp. 437 - 444 , 1998

10. Hua, Zhongsheng; Wang, Wei ; Method of product conceptual design by integrating QFD and TRIZ technical tools. In: Computer integrated manufacturing systems v.10 no.12 ,pp. 1588 - $1593,2004,1006-5911$

11. Ogot, Madara ; Conceptual design using axiomatic design in a TRIZ framework. In: Procedia engineering v.9,pp. 736 - 744, 2011 , TFC2006

12. Kamarudin, K.M. ; Ridgway, K. ; Hassan, M.R. ; Modelling the Conceptual Design Process with Hybridization of TRIZ Methodology and Systematic Design Approach. In: Procedia engineering v.131,pp. 1064 - 1072, 2015

13. Khairul Manami Kamarudin, Keith Ridgway, Mohd Roshdi Hassan; Modelling Constraints in the Conceptual Design Process with TRIZ and F3. In: Procedia CIRP, Volume 39, 2016, pp. 3-8

14. Francesco Saverio Frillici*,, Lorenzo Fiorineschi, Gaetano Cascini; Linking TRIZ to Conceptual Design Engineering Approaches. In: TFC2014 
15. Sehoon CHO and Kyeongwon LEE ; Strategic Patent Development Using TRIZ and Patent Information in Industry. In: TFC2018

16. K.M. Kamarudin, K. Ridgway, and M.R. Hassan. Modelling the conceptual design process with hybridization of TRIZ methodology and systematic design approach. TRIZ Future Conference 2014. Procedia CIRP, 2014.

17. Kamarudin, K.M. ; Ridgway, K. ; Ismail, N.; Abstraction and Generalization in Conceptual Design Process: Involving Safety Principles in TRIZ-SDA Environment. In: Procedia CIRP v.39 ,pp. 16 - 21 , 2016 , 2212-8271, TFC2015

18. Yung-Chieh Hung, Yeh-Liang Hsu; An integrated process for designing around existing patents through the theory of inventive problem-solving, In: January 1, 2007

19. Bingyi Yao, Ping Jiang, Tao Zhang, Qian Ma; A study of designing around patents based on Function Trimming. In: Management of Innovation and Technology (ICMIT), 2010 IEEE International Conference on DOI: 10.1109/ICMIT.2010. Page(s): 214 - 219

20. Ping Jiang, Jinjin Zhai, Zishun Chen, Runhua Tan; The patent design around method based on TRIZ, In: Industrial Engineering and Engineering Management, 2009. IEEM 2009. IEEE International Conference on DOI: Page(s): 1067 - 1071

21. Rosli, M.U., Ariffin, M.K.A., Sapuan, S.M., Sulaiman, S.; Integrated TRIZ-AHP Support System for Conceptual Design. In: Applied mechanics and materials v.548/549 ,pp. 1998 2002,2014

22. Young joon Gil, Etc ; Study on the Research Methodologies for Strategy-Integrated R\&D. In: SCIENCE \& TECHNOLOGY POLICY INSTITUTE, 2002

23. Sehoon Cho; US 10,084,977 Camera system and photographing method. Sep. 25, 2018

24. Sehoon Cho, Dong-jwan Won; US 8,419,880 Method of transferring Graphene. Apr..16, 2013 